\title{
I n-vitro Assessment of Effectiveness and Photostability Avobenzone in Cream Formulations by Combination Ethyl Ascorbic acid and al pha Tocopherol Acetate
}

\author{
Marline Abdassah, Ratih Aryani, Emma Surachman, Muchtaridi Muchtaridi* \\ Faculty of Pharmacy, Padjadjaran University, Sumedang, West Java, Indonesia.
}

\begin{tabular}{l} 
ARTICLE INFO \\
\hline Article history: \\
Received on: $22 / 03 / 2015$ \\
Revised on: $19 / 04 / 2015$ \\
Accepted on: $22 / 05 / 2015$ \\
Available online: $27 / 06 / 2015$ \\
\hline Key words: \\
UVA, SPF (Sun Protecting \\
Factor), erythema \\
transmission, pigmentation \\
transmission.
\end{tabular}

\section{INTRODUCTION}

The sunlight that reaches the Earth's surface is composed of ultraviolet $(200-400 \mathrm{~nm})$, visible $(400-800 \mathrm{~nm})$ and infrared (> $800 \mathrm{~nm}$ ) radiation. Ultraviolet light emitted is divided into three regions, namely the UVC (200-290 nm), UVB (290$320 \mathrm{~nm})$ and UVA I region (340-400 nm) and UVA II region (320-340 nm) (Gonzalez et al., 2007; Bonda and Marinelli, 1999; Chaudhuri et al., 2006). The skin need protect from ultraviolet radiation hazard. Sunscreen is one effort to minimize of ultraviolet radiation penetration into the skin. Indonesia is a tropical country where the sun exposure is high to require the preparation of cosmetics that acts as a sunscreen (WHO, 2013). The Environmental Working Group (EWG) that founded in 1993 by Ken Cook and Richard Wiles reviewed over 1800 sunscreens and more than 257 brands and found morethan $75 \%$ of sunscreens contain toxic chemicals that can increase the risk of cancer and other health problems. Chemical sunscreens identified hazards

\footnotetext{
* Corresponding Author

Muchtaridi Muchtaridi, Department of Pharmaceutical Analysis and Medicinal Chemistry, Faculty of Pharmacy, Universitas Padjadjaran, Indonesia.Email: muchtaridi@unpad.ac.id
}

include PABA (Para amino benzoic acid), menthylanthranilate, oxybenzone, 4-metilbenzilidin camphor, 3-benzilidin camphor, Octylmethoxycinnamate, homosalate, octisalate, and octocrylene. FDA announced to use sunscreen safety and agreed that avobenzone can be used as chemical sunscreens(EWG's, 2013). The good sunscreen should have photo-stability. Photostability is defined as the ability of a molecule to remain intact with irradiation filter or sunscreen(Gonzalez et al., 2007; Hojerova et al., 2011), because they are deliberately selected as the molecules that absorb UV radiation (Nash and Tanner, 2014).

Avobenzone is significantly degraded by UV radiation and sunlight thus the effectiveness is reduced in skin protection (Rai et al., 2012; Beasley and Meyer, 2010). One hour of sunlight exposure reduces avobenzone absorbance by $36 \%$ and mechanism stabilization of avobenzonecan be prepared by free radical scavenging (Korac and Khambholja, 2011; Gonzalez et al., 2007). SPF value and UVA filters photostability can be improved by antioxidant with potential scavenging of reactive singlet oxygen (ROS) (L'Alloret et al., 2012; Rai et al., 2012; Latha et al., 2013; Afonso et al., 2014). Vitamins $\mathrm{C}$ and $\mathrm{E}$ are antioxidants that can counteract reactive singlet oxygen (ROS) (Latha et al., 2013; Miura et al., 2008; Hojerova et al., 2011). 
The effectiveness of sun-screen preparations can be determined in-vitro by calculating the value of SPF (Sun Protection Factor), percent transmission of erythema (\% Te) and percent transmission of pigmentation (\% Tp) (Pelizzo et al., 2012; Gonzalez et al., 2007; Mishra and Chattopadhyay, 2012; Hupel et al., 2011) .

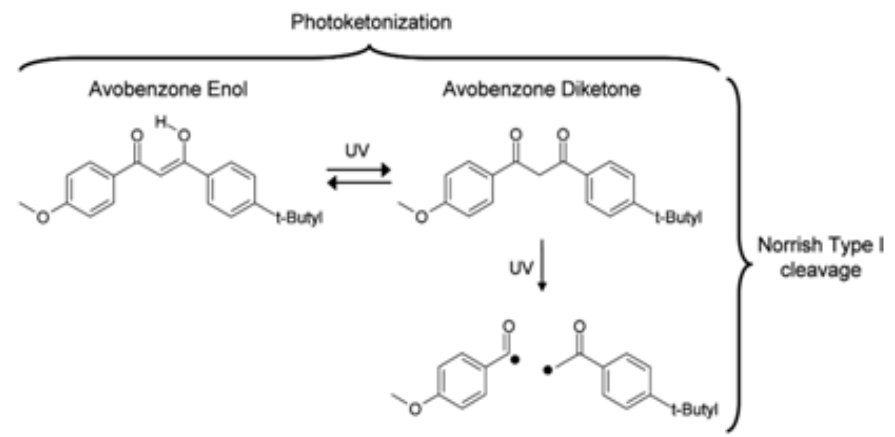

Fig. 1: Photoketonization reaction (reversible) and Norrish Type I reaction (irreversible) of Avobenzone.

The aim of this study was to determine avobenzone photostability that combined with ethyl ascorbic acid and alphatocopherol acetate to assess avobenzone levels before and after UVA lamp exposure, and determine effectiveness include the SPF value, percent transmission of erythema and pigmentation.

\section{MATERIALS AND METHOD}

\section{Chemicals}

Avobenzone, ethyl ascorbic acid, alpha tocopherol acetate were purchased from Sigma (St Louis, USA), ethanol 96\% (Merck), cream bases were purchased from local industry in Bandung, Indonesia.

\section{Apparatus}

The apparatus used included analytical balance (Sartorius), double beam Shimadzu UV/Visible spectrophotometer, UVA Lamp $4,7 \mathrm{~mW} / \mathrm{cm}^{2}$, UV radiometer, SPSS for window version 18.0, hot plate, homogenizer (IKA), rhion viscometer, $\mathrm{pH}$ strip (acid indicator), thermometer, centrifugation, ultrasonic, and other glassware commonly used in the laboratory.

\section{Stock Solution}

$20 \mathrm{mg}$ avobenzone was weighed, transferred to a $100 \mathrm{ml}$ volumetric flask, diluted to volume with ethanol $96 \%$ to give 200 $\mu \mathrm{g} / \mathrm{ml}$ solution.

\section{Maximum wavelength determination of avobenzone ( $\lambda$ max)}

The maximum wavelength is determined at a concentration of $6 \mu \mathrm{g} / \mathrm{ml}$ of avobenzone diluted with ethanol $96 \%$. The measurements were taken in the range of 200 to $400 \mathrm{~nm}$

\section{Preparation of Calibration Curve}

Appropriate dilutions of the stock solution were done separately to get $2,3,4,6,8$ and $10 \mu \mathrm{g} / \mathrm{ml}$. The absorbances were measured at $356 \mathrm{~nm}$ ( $\lambda \max$ of Avobenzone), and the calibration curves were plotted.

\section{Cream Formulations}

All of formulas was used for the preparation of oil-inwater creams containing F1 (basic as negatif control), F2 (avobenzone $2 \%$ as positive control), F3 (avobenzone $2 \%$ and ethyl ascorbic acid 0,5\%), F4 (avobenzone 2\% and ethyl ascorbic acid 1\%), F5 (avobenzone 2\% and ethyl ascorbic acid 2\%), F6 (avobenzone 2\%, ethyl ascorbic acid 0,5\%, and alpatocopherolacetatate 1\%), F7 (avobenzone 2\%, ethyl ascorbic acid $1 \%$, and alpha tocopherol acetate 1\%), F8 (avobenzone 2\%, ethyl ascorbic acid $2.0 \%$, and alpha tocopherol acetate $1 \%$ ).

\section{Evaluation of Sunscreen Cream Organoleptic observations}

Organoleptic testing was done by looking at changes in color, odor (rancidity), and the occurrence of phase separation or rupture of cream.

\section{Homogeneity test}

Homogeneity testing was observed by checking the particles size between two object glasses to determine the formation of coarse particles.

\section{pH Measurements} acid indicator.

The $\mathrm{pH}$ measurements were carried out with $\mathrm{pH}$ strip

\section{Viscosity Measurements}

The viscosity cream measurements were carried out on rhion viscometer using spindle number 2 and the measurement were carried out in triplicate and calculated the average (Kumar, et al., 2011).

\section{Centrifuge test}

Centrifuge testing has been done by centrifuging a cream preparation at a speed of $3800 \mathrm{rpm}$ for 5 hour, and phase separation was observed (Lachman et al., 1994; Elya et al., 2013).

\section{Thermal Stability}

Cream preparation stored for 1 month at room temperature $\left(28 \pm 2{ }^{\circ} \mathrm{C}\right)$, and checked every week include organoleptic, homogeneity, viscosity and $\mathrm{pH}$ (Lachman, et al., 1994).

\section{Photostability Testing of Sunscreen Cream Sample Irradiation}

Cream weighed of $0.1 \mathrm{~g}$ and placed on object, irradiated by UVA $4,7 \mathrm{~mW} / \mathrm{cm}^{2}$ for 15 hour and radiation dose gave 846 $\mathrm{KJ} / \mathrm{m} 2,1.692 \mathrm{KJ} / \mathrm{m} 2$ and $2.538 \mathrm{KJ} / \mathrm{m} 2$. This correspond to UVA dose that reaches the earth's surface during 2-5 at sunny day. For a comparison of each formula are treated without irradiation. Every 
time each formula is taken and stored in a place protected from sunlight (Venditti et al., 2008).

\section{Initial Absorbance Measurements}

Cream $(0.1 \mathrm{~g})$ was weighed, dissolved on $96 \%$ ethanol and the absorbances was measured by UV spectrophotometerat $356 \mathrm{~nm}$. Avobenzone levels were calculated using the regression line equation of calibration curve.

\section{Absorbance Measurements after UVA irradiation}

A cream $(0.1 \mathrm{~g})$ were UVA irradiation dissolved in $96 \%$ ethanol and absorbance was measured with UV spectrophotometer at $356 \mathrm{~nm}$ ( $\lambda$ max of Avobenzone), and avobenzone levels were calculated using the regression line equation of calibration curve.

\section{Evaluation}

The Data of photostability testing of avobenzone cream was performed between the level of avobenzone and length of exposure time to UV light and the significance of the differences between mean values (where $\mathrm{p}<0.05$ ) was analyzed by the block method of variance (ANAVA) from SPSS version 18.0.

\section{Effectiveness Assessment of Sunscreen Cream SPF (Sun Protection Factor)}

The cream $(0.1 \mathrm{~g})$ was weighed, further diluted in ethanol $96 \%$ to obtain $1000 \mu \mathrm{g} / \mathrm{ml}$ solution. The solution was diluted to obtain 100, 200, and $500 \mu \mathrm{g} / \mathrm{ml}$. The absorption data were obtained in the range of 290-320 nm, every $5 \mathrm{~nm}$. The SPF could be calculated followed by the application of Mandur equation (Gonzalez et al., 2007; Pelizzo et al., 2012; Sayre et al., 1980):

SPF spectrophotometric $=C F x \sum_{290}^{320} \mathrm{EF}(\lambda) \times \mathrm{I}(\lambda) \times \operatorname{Abs}(\lambda)$

Where $: \mathrm{CF}=$ correction factor $=10 ; \mathrm{EE}(\lambda)=$ erythemal effect spectrum; I $(\lambda)=$ solar intensity spectrum; Abs = absorbance of sunscreen product. The values of $\operatorname{EE}(\lambda) \times \mathrm{I}(\lambda)$ are constants. It is determined by Sayre et al (1980).

Table 1: Normalized product function used in the calculation of SPF.

\begin{tabular}{cc}
\hline Wavelenght $(\boldsymbol{\lambda} \mathbf{n m})$ & $\mathbf{E E}(\boldsymbol{\lambda}) \mathbf{x} \mathbf{I}(\boldsymbol{\lambda})$ normalized \\
\hline 290 & 0,0150 \\
295 & 0,0817 \\
300 & 0,2874 \\
305 & 0,3278 \\
310 & 0,1864 \\
315 & 0,0839 \\
320 & 0,0180 \\
Total & 1 \\
\hline
\end{tabular}

SPF assessments refer to the FDA regulations that categorize the effectiveness of sunscreen based on SPF values (Diffey and Robson, 1989). SPF assessments refer to the FDA regulations that categorize the effectiveness of sunscreen based on
SPF values (Diffey and Robson, 1989). In evaluating SPF, sample was treated at thickness of $2 \mathrm{mg} / \mathrm{cm}^{2}$, the SPF was calculated as the ratio of MED (Minimal Erythema Dose) of sunscreenprotected skin compare to the MED of unprotected skin (Haywood et al., 2003; Stephens et al., 2011).

Table 2: Prediction of SPF value.

\begin{tabular}{cc} 
SPF & Protection Category \\
\hline $2-4$ & Minimum \\
$4-6$ & Moderate \\
$6-8$ & Extra \\
$8-15$ & Maximum \\
$\geq 15$ & Ultra \\
\hline
\end{tabular}

\section{Percent Transmission of Erythema and Pigmentation}

The cream $(0.1 \mathrm{~g})$ was weighed, dissolved in ethanol $96 \%$ to obtain $1000 \mu \mathrm{g} / \mathrm{ml}$ solution. The solution has been diluted into100, 200, and $500 \mu \mathrm{g} / \mathrm{ml}$. The absorption data were obtained in the range of erythema and pigmentation wavelength 292,5$372,5 \mathrm{~nm}$, every $5 \mathrm{~nm}$ (Agustin et al., 2013). \% Te and \% Tp were calculated followed by equation:

$$
\begin{aligned}
& \% T e=\frac{\sum E e}{\sum F e} \\
& \% T p=\frac{\sum E p}{\sum F p}
\end{aligned}
$$

Where: $\% \mathrm{Te}=$ percent transmission of erythema value; $\% \mathrm{Tp}=$ percent transmission of pigmentation; $\mathrm{Ee}=\Sigma(\% \mathrm{~T} \times \mathrm{Fe}) ; \mathrm{Ep}$ $=\Sigma(\% \mathrm{~T} \times \mathrm{Fp})$.

Table 3: Transmission of erythema.

\begin{tabular}{cc}
\hline Wavelength Range $(\mathbf{n m})$ & Erythema Fluks $(\mathbf{F e})$ \\
\hline $290-295$ & 0.1105 \\
$295-300$ & 0.6720 \\
$300-310$ & 1.0000 \\
$310-315$ & 0.2008 \\
$315-320$ & 0.1125 \\
\hline
\end{tabular}

Table 4: Transmission of Pigmentation.

\begin{tabular}{cc}
\hline Wavelength Range $(\mathbf{n m})$ & Pigmentation Fluks $(\mathbf{F p})$ \\
\hline $320-325$ & 0.1079 \\
$325-330$ & 0.1020 \\
$330-335$ & 0.0936 \\
$335-340$ & 0.0798 \\
$340-345$ & 0.0669 \\
$345-350$ & 0.0570 \\
$350-355$ & 0.0488 \\
$355-360$ & 0.0456 \\
$360-365$ & 0.0356 \\
$365-370$ & 0.0310 \\
\hline
\end{tabular}

Table 5: Rating Sunscreen Category.

\begin{tabular}{ccc}
\hline $\boldsymbol{\%} \mathbf{T e}$ & $\mathbf{\%} \mathbf{T} \mathbf{p}$ & Sunscreen Category \\
\hline$<1$ & $3-40$ & Sun block \\
$1-6$ & $42-86$ & Ultra protection \\
$6-12$ & $45-86$ & Suntan \\
$10-18$ & $45-86$ & Fast Taning \\
\hline
\end{tabular}


Table 6: The results of measurement of cream absorbances before and after UVA irradiation

\begin{tabular}{|c|c|c|c|c|c|}
\hline \multirow{2}{*}{ Formula } & \multirow{2}{*}{$\begin{array}{c}\text { Avobenzone level before } \\
\text { irradiation }(\%)\end{array}$} & \multicolumn{3}{|c|}{ Avobenzone level after irradiation (\%) } & \multirow{2}{*}{$\begin{array}{c}\text { Avobenzone level } \\
\text { decreased }(\%)\end{array}$} \\
\hline & & 5 jam & 10 jam & 15 jam & \\
\hline F1 & $115.87 \pm 0.119$ & $107.21 \pm 0.05$ & $95.94 \pm 0.063$ & $86.50 \pm 0.065$ & 29.37 \\
\hline $\mathrm{F} 2$ & $117.02 \pm 0.141$ & $107.15 \pm 0.087$ & $97.11 \pm 0.241$ & $88.27 \pm 0.260$ & 28.75 \\
\hline F3 & $111.72 \pm 0.174$ & $104.82 \pm 0.304$ & $98.92 \pm 0.074$ & $91.03 \pm 0.145$ & 20.69 \\
\hline F4 & $112.02 \pm 0.048$ & $109.64 \pm 0.395$ & $105.34 \pm 0.378$ & $100.18 \pm 0.059$ & 11.84 \\
\hline F5 & $116.25 \pm 0.144$ & $106.03 \pm 0.032$ & $96.72 \pm 0.233$ & $88.82 \pm 0.257$ & 27.43 \\
\hline F6 & $119.40 \pm 0.246$ & $110.75 \pm 0.292$ & $101.12 \pm 0.253$ & $91.79 \pm 0.118$ & 27.61 \\
\hline F7 & $117.04 \pm 0.104$ & $110.04 \pm 0.08$ & $104.91 \pm 0.143$ & $99.30 \pm 0.024$ & 17.74 \\
\hline F8 & $115.10 \pm 0.091$ & $111.22 \pm 0.145$ & $104.93 \pm 0.140$ & $97.32 \pm 0.165$ & 17.78 \\
\hline
\end{tabular}

Table 7: The Results of Effectiveness - SPF (Sun Protection Factor) Testing.

\begin{tabular}{|c|c|c|c|c|}
\hline \multirow{2}{*}{ Formula } & \multicolumn{4}{|c|}{ SPF value } \\
\hline & $100 \mu \mathrm{g} / \mathrm{ml}$ & $200 \mu \mathrm{g} / \mathrm{ml}$ & $500 \mu \mathrm{g} / \mathrm{ml}$ & $1000 \mu \mathrm{g} / \mathrm{ml}$ \\
\hline Formula 0 (Negative control) & 0,039 & 0,110 & 0,415 & 0,987 \\
\hline Formula 1 (Positive control) & 0,524 & 1,136 & 2,911 & 5,889 \\
\hline Formula 2 & $0,5 \mathrm{~s} 63$ & 1,144 & 2,918 & 6,024 \\
\hline Formula 3 & 0,584 & 1,146 & 2,931 & 6,024 \\
\hline Formula 4 & 0,594 & 1,209 & 3,043 & 6,190 \\
\hline Formula 5 & 0,570 & 1,173 & 2,972 & 6,074 \\
\hline Formula 6 & 0,611 & 1,227 & 3,091 & 6,250 \\
\hline Formula 7 & 0,621 & 1,239 & 3,128 & 6,278 \\
\hline Formula 8 & 0,633 & 1,323 & 3,136 & 6,407 \\
\hline
\end{tabular}

Table 8: The Results of Effectiveness - Percent Transmission of Erythema and Pigmentation at $100 \mu \mathrm{g} / \mathrm{ml}$.

\begin{tabular}{|c|c|c|c|}
\hline Formula & $\% \mathrm{Te}$ & $\% \mathrm{Tp}$ & Effectiveness Category \\
\hline Formula 0 ( Negative control ) & 98,834 & 101,462 & Ineffectiveness \\
\hline Formula 1 ( Positive control ) & 88,844 & 67,549 & Ultra Protection of UVA \\
\hline Formula 2 & 87,904 & 67,017 & Ultra Protection of UVA \\
\hline Formula 3 & 87,736 & 67,041 & Ultra Protection of UVA \\
\hline Formula 4 & 87,132 & 65,844 & Ultra Protection of UVA \\
\hline Formula 5 & 87,629 & 66,787 & Ultra Protection of UVA \\
\hline Formula 6 & 87,116 & 68,309 & Ultra Protection of UVA \\
\hline Formula 7 & 86,756 & 65,937 & Ultra Protection of UVA \\
\hline Formula 8 & 86,631 & 65,844 & Ultra Protection of UVA \\
\hline
\end{tabular}

Table 9: The Results of Effectiveness - Percent Transmission of Erythema and Pigmentation at $200 \mu \mathrm{g} / \mathrm{ml}$

\begin{tabular}{|c|c|c|c|}
\hline Formula & $\% \mathrm{Te}$ & $\% \mathbf{T p}$ & Effectiveness Category \\
\hline Formula 0 (Negative control) & 97,219 & 99,554 & $\begin{array}{l}\text { Ineffectiveness } \\
\end{array}$ \\
\hline Formula 1 (Positive control) & 77,208 & 45,795 & Ultra Protection of UVA \\
\hline Formula 2 & 77,222 & 45,491 & Ultra Protection of UVA \\
\hline Formula 3 & 77,184 & 45,632 & Ultra Protection of UVA \\
\hline Formula 4 & 75,932 & 43,700 & Ultra Protection of UVA \\
\hline Formula 5 & 76,949 & 45,214 & Ultra Protection of UVA \\
\hline Formula 6 & 75,851 & 44,202 & Ultra Protection of UVA \\
\hline Formula 7 & 75,794 & 42,576 & Ultra Protection of UVA \\
\hline Formula 8 & 74,234 & 43,650 & Ultra Protection of UVA \\
\hline
\end{tabular}

Table 10: The Results of Effectiveness - Percent Transmission of Erythema and Pigmentation at $500 \mu \mathrm{g} / \mathrm{ml}$.

\begin{tabular}{|c|c|c|c|}
\hline Formula & $\% \mathrm{Te}$ & $\% \mathbf{T p}$ & Effectiveness Category \\
\hline Formula 0 (Negative control) & 90,561 & 93,217 & Ineffectiveness \\
\hline Formula 1 (Positive control) & 51,956 & 15,414 & UVA Sunblock \\
\hline Formula 2 & 52,092 & 15,284 & UVA Sunblock \\
\hline Formula 3 & 51,996 & 15,211 & UVA Sunblock \\
\hline Formula 4 & 50,652 & 13,771 & UVA Sunblock \\
\hline Formula 5 & 51,337 & 15,003 & UVA Sunblock \\
\hline Formula 6 & 49,977 & 14,336 & UVA Sunblock \\
\hline Formula 7 & 49,511 & 13,661 & UVA Sunblock \\
\hline Formula 8 & 49,516 & 14,357 & UVA Sunblock \\
\hline Formula & $\% \mathrm{Te}$ & $\% \mathrm{Tp}$ & Effectiveness Category \\
\hline Formula 0 (Negative control) & 79,365 & 82,322 & Ultra Protection of UVA \\
\hline Formula 1 (Positive control) & 26,889 & 2,940 & UVA Sunblock \\
\hline Formula 2 & 26,200 & 2,883 & UVA Sunblock \\
\hline Formula 3 & 26,072 & 2,840 & UVA Sunblock \\
\hline Formula 4 & 25,179 & 2,473 & UVA Sunblock \\
\hline Formula 5 & 25,750 & 2,903 & UVA Sunblock \\
\hline Formula 6 & 24,762 & 2,582 & UVA Sunblock \\
\hline Formula 7 & 24,570 & 2,721 & UVA Sunblock \\
\hline Formula 8 & 23,915 & 2,407 & UVA Sunblock \\
\hline
\end{tabular}

Keterangan : \% Te = Percent transmission of erythema value., \% $\mathrm{Tp}=$ Percent transmission of pigmentation value 


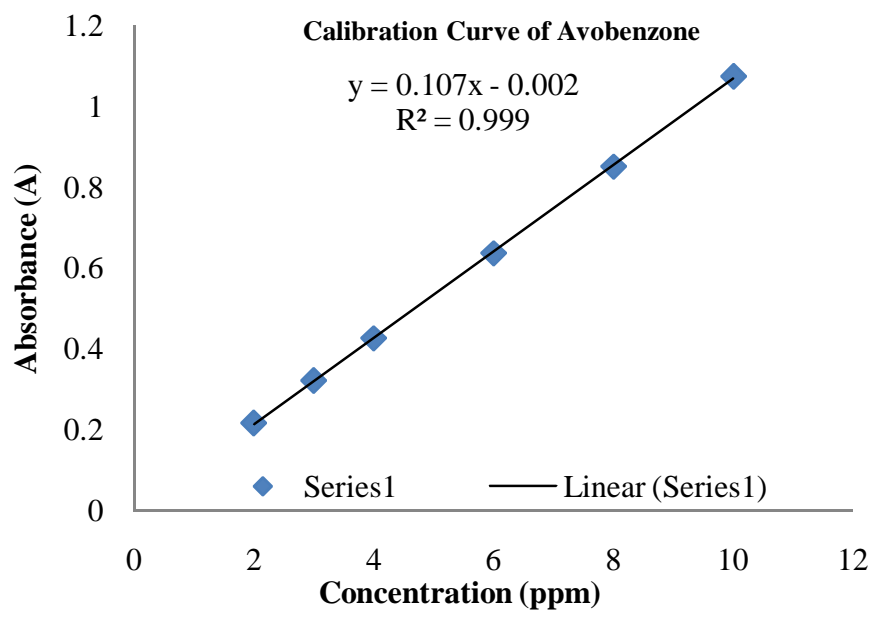

Fig. 2: Calibration Curve of Avobenzone ( $\lambda 356 \mathrm{~nm})$.

\section{CONCLUSIONS}

The results of analysis of variance showed that the addition of ethyl ascorbic acid and alpha tocopherol acetate in cream formula gave the significant difference photostability with the formula 1 (avobenzone 2\%) with 95\% confidence level $(\mathrm{p} \leq 0,05)$. The formula 4 (avobenzone $2 \%$ and $2 \%$ ethyl ascorbic acid) was the best formula to stabilize avobenzone in preparation.

The addition of ethyl ascorbic acid and alpha tocopherol acetate might improved the SPF value, but have been not able to improve the effectiveness of protection against erythema/UVB. While, the value of percent transmission of erythema (Te) and percent transmission of pigmentation (Tp) decreased.

\section{REFERENCES}

Afonso, S., Horita, K., Sousa e Silva, J. P., Almeida, I. F., Amaral, M. H., Lobao, P. A., Costa, P. C., Miranda, M. S., Esteves da Silva, J. C., and Sousa Lobo, J. M. Photodegradation of avobenzone: stabilization effect of antioxidants. J Photochem Photobiol B, 2014; 140:36-40.

Agustin, R., Yulida, O., and Henny, L. Formulasi Krim Tabir Surya Dari Kombinasi Etil p-Metoksisinamat dengan Katekin. In Seminar Nasional Perkembangan Terkini Sains Farmasi dan Klinik III, 2013; 184198.

Beasley, D. G., and Meyer, T. A. Characterization of the UVA protection provided by avobenzone, zinc oxide, and titanium dioxide in broad-spectrum sunscreen products. Am J Clin Dermatol, 2010; 11 (6):413-421.

Bonda, C., and Marinelli, P. 1999. The photochemistry of sunscreen photostability. Paris: 46 - 51.

Chaudhuri, R., Lascu, Z., Puccetti, G., Deshpande, A., and Paknikar, S. Design of a photostabilizer having built-in antioxidant functionality and its utility in obtaining broad-spectrum sunscreen formulations. Photochem Photobiol, 2006; 82:823 - 828.

Diffey, B., and J. Robson. A new substrate to measure sunscreen protection factors throughout the ultraviolet spectrum. J Soc Cosmet Chem, 1989; 40:127-133.

EWG's. Cosmetics Database. 2013. [cited. Available from http://www.ewg.org/skindeep/ingredient/700596/AVOBENZONE/.

Gonzalez, H., Tarras-Wahlberg, N., Stromdahl, B., Juzeniene, A., Moan, J., Larko, O., Rosen, A., and Wennberg, A.-M. Photostability of commercial sunscreens upon sun exposure and irradiation by ultraviolet lamps. BMC Dermatology, 2007; 7 (1):1.
Haywood, R., Wardman, P., Sanders, R., and Linge, C. Sunscreens inadequately protect against ultraviolet-A-induced free radicals in skin: implications for skin aging and melanoma? J Invest Dermatol, 2003; 121 (4):862-868.

Hojerova, J., Medovcikova, A., and Mikula, M. Photoprotective efficacy and photostability of fifteen sunscreen products having the same label SPF subjected to natural sunlight. Int J Pharm, 2011; 408 (1-2):2738 .

Hupel, M., Poupart, N., and Gall, E. A. Development of a new in vitro method to evaluate the photoprotective sunscreen activity of plant extracts against high UV-B radiation. Talanta, 2011; 86:362-371.

Korac, R. R., and Khambholja, K. M. Potential of herbs in skin protection from ultraviolet radiation. Pharmacogn Rev, 2011; 5 (10):164173.

L'Alloret, F., Candau, D., Seite, S., Pygmalion, M. J., Ruiz, L., Josso, M., Meaudre, H., Gauchet, L., Pena, A. M., and Colonna, A. New combination of ultraviolet absorbers in an oily emollient increases sunscreen efficacy and photostability. Dermatol Ther (Heidelb), 2012; 2 (1):4.

Latha, M. S., Martis, J., Shobha, V., Sham Shinde, R., Bangera, S., Krishnankutty, B., Bellary, S., Varughese, S., Rao, P., and Naveen Kumar, B. R. Sunscreening agents: a review. J Clin Aesthet Dermatol, 2013; 6 (1):16-26.

Mishra, A., and Chattopadhyay, P. Assessment of In vitro Sun Protection Factor of Calendula Officinalis L. (Asteraceae) Essential Oil Formulation. J Young Pharm, 2012; 4 (1):17-21.

Miura, Y., Takiguchi, Y., Shirao, M., Takata, S., Yanagida, T., Fukui, H., Naganuma, M., and Hatao, M. Algorithm for in vitro Sun Protection Factor based on transmission spectrum measurement with concomitant evaluation of photostability. Photochem Photobiol, 2008; 84 (6):1569-1575.

Nash, J. F., and Tanner, P. R. Relevance of UV filter/sunscreen product photostability to human safety. Photodermatol Photoimmunol Photomed, 2014; 30 (2-3):88-95.

Pelizzo, M., Zattra, E., Nicolosi, P., Peserico, A., Garoli, D., and Alaibac, M., 2012, In vitro evaluation of sunscreens: an update for the clinicians. ISRN Dermatol, 2012:352135.

Rai, R., Shanmuga, S. C., and Srinivas, C. Update on photoprotection. Indian J Dermatol, 2012; 57 (5):335-342.

Sayre, M. R., Patricia Poh Agin, Deborah L. Desrochers, and Marlowe, E. Sunscreen testing method s: In vitro predictions of effectiveness. Soc Cosm Chem, 1980; 31:133-143.

Stephens, T. J., Herndon, J. H., Jr., Colon, L. E., and Gottschalk, R. W. The impact of natural sunlight exposure on the UVBsun protection factor (UVB-SPF) and UVA protection factor (UVA-PF) of a UVA/UVB SPF 50 sunscreen. J Drugs Dermatol, 2011; 10 (2):150-155.

Sugihartni, N., Marchaban, Pramono, dan Suwidiyo. Pengaruh Penambahan Fraksi etanol dari Infusa daun Plantago mayor L. Terhadap Efektivitas Oktil Metoksisinamat Sebagai Bahan Aktif Tabir Surya. Majalah Farmasi Indonesia, 2005; 16 (3):130-135.

Venditti, E., Spadoni, T., Tiano, L., Astolfi, P., Greci, L., Littarru, G. P., and Damiani, E. In vitro photostability and photoprotection studies of a novel 'multi-active' UV-absorber. Free Radic Biol Med, 2008; 45 (3):345-354.

WHO. 2003, Sun Protection A Primary Teaching Resouce. France : WHO. World Health Organization 2013 [cited 03/22/2015 2003]. Available from http://www.who.int/uv/publications/en/primaryteach.pdf.

\section{How to cite this article:}

Marline Abdassah, Ratih Aryani, Emma Surachman, Muchtaridi Muchtaridi. In-vitro Assessment of Effectiveness and Photostability Avobenzone In Cream Formulations By Combination Ethyl Ascorbic acid and alpha Tocopherol Acetate. J App Pharm Sci, 2015; 5 (06): 070-074. 